\title{
Controlling Facial Selectivity Towards Carbocations via a Docking Strategy
}

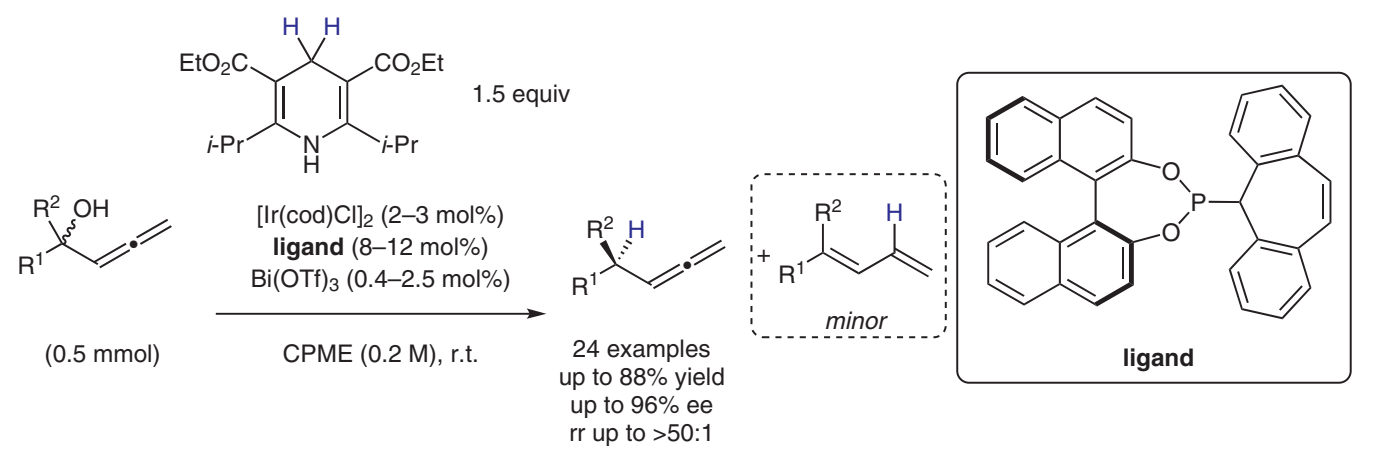

Selected examples:

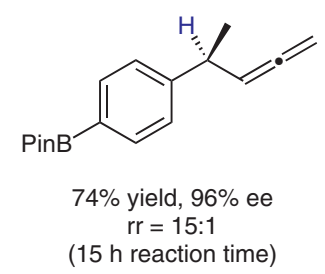

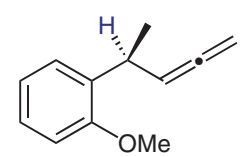

$64 \%$ yield, $73 \%$ ee rr > 20:1

(13 $\mathrm{h}$ reaction time)<smiles>C=CC(c1ccc(F)cc1OC)C1CC1</smiles>

$79 \%$ yield, $95 \%$ ee rr > 50:1

(13 $\mathrm{h}$ reaction time)



$72 \%$ yield, $38 \%$ ee

$$
\text { rr }>20: 1
$$

( $21 \mathrm{~h}$ reaction time)

Postulated mechanism:

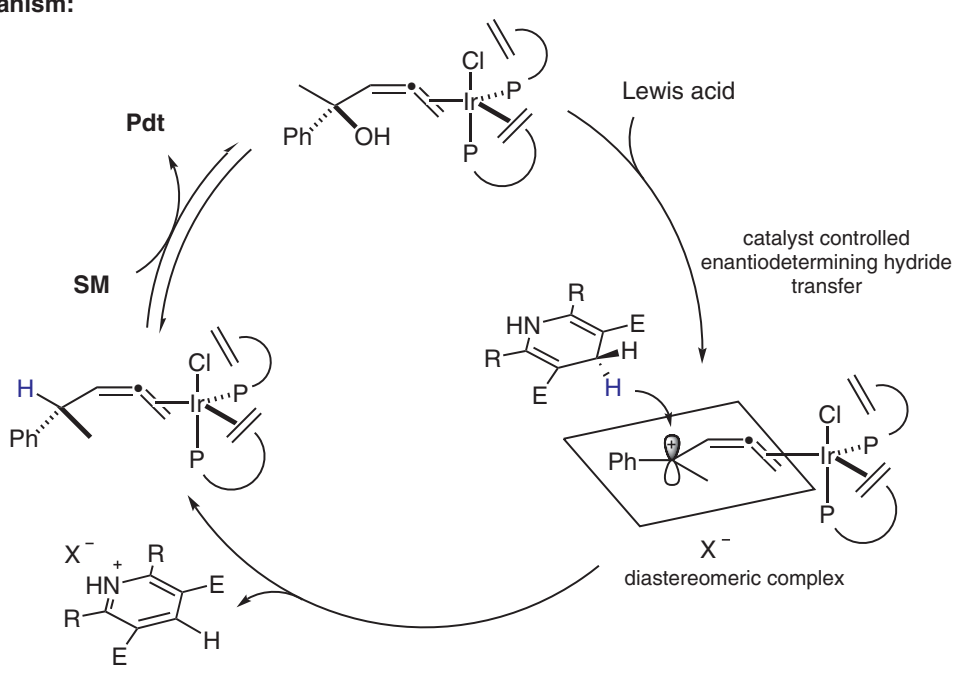

Significance: Reliable facial selectivity in nonchiral carbocations would be a powerful methodology allowing for numerous asymmetric transformations. The formation of a carbocation on a chiral metal complex would allow for subsequent enantioselective attack onto the resulting carbocation. The authors use this strategy and demonstrate a broad scope with moderate to good yields and excellent enantioselectivities.

\section{Key words}

iridium catalysis

reductive deoxygenation

allenes

Comment: The analogous reaction on an allylic system led to none of the desired product, suggesting that the extra carbon spacer is necessary to avoid steric congestion. In addition, the authors obtained an X-ray structure of the key allene-iridium complex, which supports the conclusion that the terminal olefin of the allene docks into the iridium complex. 